\title{
Health status and the development of health services in a colonial state: the case of British Malaya
}

\begin{abstract}
The health of a population and the development of health services in a country at a particular time in history are directly linked to the socioeconomic system. This paper discusses health and health services in the Malay Peninsula during the time that it was a British colony. Economic production under British colonialism, which is basically a capitalist system, is organized primarily for the purpose of realizing profits. The health of the population is in direct conflict with and generally subordinated to this main objective. The pattern of health that emerges reflects this general framework. Moreover, health services under the colonialist system are developed primarily to serve the economic interests of the colonialists. Hence, the structure of health services is biased toward curative medicine and centered mainly in the urban areas.
\end{abstract}

Keyword: Health; Health services; Malay Peninsula; British colony 